\title{
Implementation of Applied Physical Education with Students with Disabilities in High School
}

\author{
Dmitriy Valerievich Viktorov* \\ Department of Physical Education and Health, South Ural State University, Russia
}

Submission: March 16, 2018; Published: March 27, 2018

*Corresponding author: Dmitriy Valerievich Viktorov, Department of Physical Education and Health, South Ural State University, Russia; Email: viktorovdv@yandex.ru

\begin{abstract}
Problem Statement: Questions professionally-applied physical training of students with disabilities require intensive search for optimal ways of organizing learning, which will provide a high level of professional adaptation of future employment.

Approach: The paper discusses the algorithm of activities to update the application of various tools, techniques and methods applied physical culture to promote occupational adaptation, which achieved substantial characteristics of personality physical culture. The purpose of our research was to study the conditions to ensure continuous applied physical education of students with disabilities in the educational process of the University in accordance with the experimental two practical lessons per week. The object of research was the process of professionallyoriented physical education in the educational process of the University. The results of research suggest that creating in the University educational space applied physical education, involving the selection of the adequate health of student's means of professional-applied physical training of functional capabilities involved in to form professional adaptation, contribute to a more successful vocational training and further it improvements.
\end{abstract}

Conclusion: Gradually involving students with disabilities in applied physical preparation, it is possible to reduce the period of adaptation to physical loads, thus increasing motor readiness and further professional development.

Keywords: Students; Application; Readiness; Profession; Health; Physical Education; System; Pedagogy; Education; University

\section{Introduction}

The influence of professional-applied physical training on formation of readiness to work in the educational process of the University widely, constantly conceptualized, re-measured, leading to a more holistic view of the training [1]. Currently reduced the number of healthy people increases from the first to the third course of special medical department, released for health reasons from physical education classes students receive tests on the results of knowledge of theory or medical certificates. Students with deviations in health status of temporary or permanent nature require significant restrictions on physical activity taking into account the performance and functional features, many not fully ready to perform the standard training applied physical training.

It can be assumed that in this case, a professional adaptation to the content of the labour activity, as a natural result of professional education, education and self-education, selfidentity and a comprehensive outcome measure PFP graduate any profile of students with disabilities is inappropriate to the requirements of physical reliability and readiness for the future profession, and is of particular importance. Thus, actualizarea the problem of practical training of students with disabilities, the result of which appears to personal property in the form of professional adaptation [2,3].

\section{Material and Methods}

Adaptation is a process of active adaptation, the development of the personality of the new social conditions. Activities in the process of professional adaptation acts as a link in maintaining an optimal balance the changing environmental conditions of relative stability functions, providing a single, integrated process the relationship of the individual and the profession [4]. The formation of professional adaptation changes as a result of special training, indicating achievement of the subject of the appropriate level of professional activity, the basis of manifestation of competence and the formation of competitiveness.

Practice shows that scientific and methodological support of this process for students with disabilities does not always give the desired effect: on the one hand, students are limited to carry out applied training activities within the range of possibilities of 
his health. Other teachers do not possess in sufficient degree the necessary knowledge needed for understanding of essence of pathological processes occurring in the body in various diseases, show undue passivity and inertia in this important work, with significant impact on functional fitness and, ultimately, on the process of human adaptation to the changing conditions of his life [5].

\section{Participants}

In the study, students of SUSU (NRU) and South Ural State Institute of Arts named after PI Tchaikovsky referred to the main and preparatory groups took part. Well-known and widely used functional tests were used to assess the speed of adaptation of the body to physical activity or mainly showing the development of any quality. Classes of vocational and applied training to students South Ural State Institute of Arts was carried out in the normal traditional mode. Classes with students of the SUSU were conducted according to the phased structure of involvement in applied physical education, regardless of specialty, allowing students with disabilities to reduce the period of adaptation to physical stress and thus to improve motor ability in a consistent organization of educational process at the twice-a-day lessons per week: General physical training, vocational and applied physical training, specialization in the chosen form of exercise. The distribution of the loads is presented in Table 1.

Table 1: Planning and periodisation practical training of students with disabilities.

\begin{tabular}{|c|c|c|c|}
\hline \multirow{2}{*}{ Periods of Academic Work } & 1 Course & 2 Course \\
\cline { 2 - 4 } & \multicolumn{2}{|c|}{ The Stages and Tasks of the Educational Process } \\
\hline $1,3,5$ semesters & $\begin{array}{c}\text { Adaptation of students to physical } \\
\text { activity }\end{array}$ & $\begin{array}{c}\text { The restoration of physical health } \\
\text { The development of special } \\
\text { qualities }\end{array}$ & $\begin{array}{c}\text { Application of skills application } \\
\text { focus }\end{array}$ \\
\hline $2,4,6$ semesters & $\begin{array}{c}\text { The development of the skills } \\
\text { application focus }\end{array}$ & $\begin{array}{c}\text { Improving the skills application } \\
\text { focus }\end{array}$ \\
\hline
\end{tabular}

The result of formation of professional adaptation of students with disabilities in the process of applied physical education was the criteria: adaptability (process directed adaptation of the body to training stress), test for index Rufe; the recoverability of (the process of returning the body to pedrobotero condition), an indicator of which is the pulse and blood pressure (Martin-

Table 2: Dynamics of indicators of professional adaptation.

Kucherevskiy's test); elaboration (changes in the fields of functional systems during physical activity), the test of the three-phase breath-hold (Serkin's test).

\section{Result}

Changes of indicators of professional adaptation are presented in Table 2.

\begin{tabular}{|c|c|c|c|c|}
\hline \multirow{2}{*}{ Indicators } & \multirow{2}{*}{ High School } & \multicolumn{3}{|c|}{ Investigation Phase } \\
\cline { 2 - 4 } & & $\mathbf{2 0 1 4 - 2 0 1 5}$ & $\mathbf{2 0 1 5 - 2 0 1 6}$ & $\mathbf{2 0 1 6 - 2 0 1 7}$ \\
\hline \multirow{2}{*}{ Index Rufe } & SUSU & $12,9 \pm 2,9$ & $11,5 \pm 2,4$ & $9,7 \pm 1,8$ \\
\cline { 2 - 5 } & SUSI of Arts & $13,1 \pm 2,8$ & $11,2 \pm 2,3$ & $10,1 \pm 1,6$ \\
\hline \multirow{2}{*}{ Martin-Kucherevskiy's test } & SUSU & $39 / 61^{*}$ & $64 / 36^{*}$ & $74 / 26^{*}$ \\
\cline { 2 - 5 } & SUSI of Arts & $43 / 57^{*}$ & $61 / 39^{*}$ & $69 / 31^{*}$ \\
\hline \multirow{2}{*}{ Serkin's test } & SUSU & $46,3 / 86,7^{* *}$ & $48,2 / 97,5^{* *}$ & $59,5 / 103,4^{* *}$ \\
\cline { 2 - 5 } & SUSI of Arts & $46,7 / 91,9^{* *}$ & $48 / 103,1^{* *}$ & $64,6 / 116,4^{* *}$ \\
\hline
\end{tabular}

Note: *The number of students (\%) type of reaction: Favorable (normal)/unfavorable (Hypo,Hyper,Dis,Speed); ** $2^{\text {nd }}, 3^{\text {rd }}$ stages $(\%)$.

\section{Discussion}

The requirement of readiness for professional activity of a modern specialist is pronounced applied of physical culture means associated with the nature of the forthcoming work. In our work, we give the definition of the notion "applied physical education" is a pedagogical process sufficient and adequate vocational and applied physical training, regardless of the factors and conditions of the chosen professional activity, able to provide the students with deviations in health status of professionally important qualities that contribute to successful functional training, reflecting an increase of range of adaptation possibilities of organism.
Analysis of the study showed that the students of SUSI of Arts alone does not use of professional-applied physical training, do not attend regularly applied sports and physical education, motives to self-employment exist in the form of vague desires and goals, can be seen the motif classes only for a test on the subject, the level of professionally important qualities are low. The observed changes are associated with the physical characteristics of individuals in the sample and are not natural.

The students of SUSU in the classroom use knowledge of professional-applied physical preparedness, self-justified and form the goals and objectives applied in the preparation, plan and carry out self-monitoring of dynamics of professionally 
important qualities. In addition to visits classes on the subject of active physical self-improvement, are interested in information on methods of independent classes, go on personal Wellness project independently extract the necessary information, possess the diagnostic skills of self-control, able to regulate the amount and intensity of physical activity. Appear inner motivations to improve individual level of physical fitness. Deliberately selected means of professional-applied physical training in accordance with the possibilities of health. The levels of development of physical qualities are transferred from low to higher and were estimated as "good" or "excellent".

\section{Conclusion}

Based on the analysis of theoretical sources and real practice found that applied physical education is an educational system that unites the subjects of the educational space is not a way of assigning samples to a variety of applied pedagogical practices that are necessary in the workforce, and the creation of new universal knowledge of how personal educational product, opening an innovative way of applying the conceptual model, pedagogical conditions, technologies for their implementation in the process of formation of professional adaptation of future professionals with disabilities for professional activities.

Applied physical education is not opposed to physical education, while simultaneously serving as a means of a comprehensive physical fitness and Vice versa, it should go parallel to it throughout the study period, but the proportion of one or the other preparation may vary depending on the nature of deviations in the health status of students over a specific period, and in every lesson.

\section{References}

1. Korovin SS (2005) Theory and methods of formation of physical culture of personality. OGPU Publishing House, Orenburg, Russia.

2. Viktorov DV (2017) Formation of readiness for professional activity of students of SUSU. Man, Health, Physical Culture and Sport in a Changing World: XXVII International Scientific and Practical Conference on Physical Education of Students. MGOSSGI, Kolomna, Russia, pp. 327330 .

3. Zagvyazinsky VI (2010) Pedagogical science and education reform. Public Education 2: 42-43.

4. Apanasenko GL, Popova LA (2000) Medical Valeology. Phoenix, Rostov, Russia, pp. 248.

5. Kabachkova AV, Fomchenko VV, Yu S Frolov (2015) The motor activity of the youth student. Vestn Tom state un-ta, Russia, 392: 175-178.

Your next submission with Juniper Publishers
will reach you the below assets
- Quality Editorial service
- Swift Peer Review
- Reprints availability
- E-prints Service
- Manuscript Podcast for convenient understanding
- Global attainment for your research
- Manuscript accessibility in different formats
( Pdf, E-pub, Full Text, Audio)
- Unceasing customer service
Track the below URL for one-step submission
https://juniperpublishers.com/online-submission.php

